wards, thus grasping the muscles so that when traction is made on the calico band the muscles with the patella are drawn downwards. This band is passed through the slit, in the splint and a loop is made in it at that level, through which a bar similar to the one in the hollowed heel is passed, and then by stronger or weaker elastic bands, attached round the ends of the bars, greater or less traction on the muscles inserted into the patella can be made. The patient returned home by rail after this splint had been affixed some days and wore it for six weeks, after which the knee was put up in plaster-of-Paris for a fortnight. Passive motion and massage were then practised, the stiffness gradually wearing off, he being able in a week or two, wearing one of Dr. Fisher's flexible knee-caps, to walk about with the aid of a stick. Now at an interval of three years and a half he is able to use the leg freely, and says he has to think before he can remember which was the injured leg, the muscles having a firm point of fixation in the new tissue. The measurement between the lower border of the patella and the npper border of the tuberosity of the tibia is now ore inch. The patient is subject to chronic albuminuria, but this has not affected the process of repair.

King's Parade, cliiton.

\section{MUMMIFICATION OF A FGTUS IN THE UTERUS.} BY JAMES OLIVER, M.D., F.R.S. EDIN.

A woman aged twenty-six and married eight years has had four children but no miscarriage. The last child was born twenty-seven months ago and was suckled for two years. After this confinement the menstrual discharge reappeared when the cbild was fifteen months old and it recurred regularly every month until March 24th. From this date until Aug. 15th there was complete amenorrhoea. On Aug. 15th she complained of pain in the lower abdomen and simultaneously she noted the existence of a slight hæmorrhagic discharge from the vagina. The pain, which was never setere, and the hæmorrhage, which was slight, continued for seven days. Between Aug. 22nd and Sept. 21st-the date on which the patient came under my observationnothing worthy of note had occurred. On Sept. 21st the physical signs were as follows. Nothing was revealed by abdominal examination. Vaginally the cervix, which was not soft, was directed towards the left side of the pelvis In front of the corvix and on the right side was felt a somewhat lobulated swelling about the size of a small cocoa-nut; this swelling was the body of the uterus As I considered the history and physical signs to be in keeping with the existence of a mummified fotus in the uterus the patient was admitted into hospital. On Oct. 21st patient again began to complain of pain and simultaneously there was observed a free discharge of blood from the vagina On the following day an almost round mass was expelled. The longitud al diameter of this mass was three inches and the transverse two inches and a halt. The greater part of the mass was placental it was lobulated and fibrous looking. Through a thinned portion of the mass the fotus enclosed in its own membrane was expelled. The cavity in which the fotus had lain was lined by another distinct membrane.

Description of the foetus.-It is five inches long and the head is disproportionately large. The eyelids are open, but no part of the eyeball can be distinguished. No definite hairs can be made out on the scalp. The mouth is large and open and the tongue protrudes slightly. The fingers and tocs are distinct, but the presence of nails is doubtful. The umbilicus is at the lower end of the middle third of the linea alba. There is no remnant of the cord. The labia majora are distinct and the clitoris is comparatively large.

It is more than probable that this patient conceived soon after March 24th, that death of the fotus occurred on or about Aug. 15th, and that the process of mummification extended from this date until Oct. 22 nd, the date on which the contents of the uterus were expelled.

Gordon-square, W.C.

\section{TWO CASES OF STRANGULATED FEMORAL HERNIA WITH RECOVERY AF'TER OPERA'TION.}

By Chesman Barker, M.B., L.R.C.P.Lond., M.R.C.S.

THE following cuses may be of interest to the readers of 'THE JAANCW' as showing the success which follows early Ireatuent of strangulated femoral hernia by operation, even though performed by surgeons unskilled in herniotomy, and without the manifest advantages pertaining to operations performed in hospital. That a femoral hernia when strangulated is a very much more serious affair than an inguinal hernia in the same condition is well known, but the comparative mortality is perhaps not appreciated at its proper ratio by the profession generally. The statistics of St. Bartholomew's Hospital for the year 1891, collected by Messrs. Bowlby and Lockwood, show that thirty-one operations for strangulated hernia were performed in that year, and that of these six were for inguinal and twenty-five were for femoral hernix. Of the inguinal cases none died, giving for that year a mortality of 0 per cent. Of the femoral cases eleven died, giving a mortality of 44 per cent. It is probable that this greatly increased mortality is largely due to the fact that the intestine is damaged so rapidly in femoral hernia by the unyielding margins of the ring that the delay which generally takes place in conveying a patient to a hospital is sufficient to allow the intestine to be injured beyond recovery. Thatfemoral hernia is not more dangerous than the inguinal variety, if operated upon in time, is probable, and in support of this statement I give below two cases of femoral herniæ in which operation within two hours of recognising the condition was followed by rapid recovery. In both cases the intestine was quite uninjured, being only a little congested ; and it is highly probable that if time had been wasted in sending these patients to a hospital, or if one had had to send many miles for a surgeon, the intestine would have fallen into a condition rendering the operation one of difficulty and danger instead of the easy and successful measure it proved to be.

Case 1.-On March 31st, 1892, I was called to see Mrs. H. W - a aged thirty years, whom I found to be suffering from a strangulated right femoral hernia. The hernia bad existed for several years, but she had nevar worn any truss. She had been in the habit of putting it back herself, but on March 28th it became painful and she was unable to reduce it. Next morning she was in considerable pain and was vomiting, and the bowels had not been moved. On the following day when I saw her she was in great pain and her tongue was dry and furred, and her expression was anxious. The hernia was tense and tender, was irreducible and had no impulse on cough. I therefore at once decided to operate, anò, ihe patient being put under the A.C.E. mixture, a vertical incision was made over the swelling, and the sac being opened on a director showed that the contents consisted chiefly of omentum. A small incision of Gimbernat's ligament easily allowed of the reduction of the intestine; the omentum being firmly adherent along the outer side of the femoral canal was ligatured and cut off, as also the redundant portion of the sac after the neck had been sewn up with silk ligatures; the skin wound was united with silk sutures and an indiarubber drainage-tube inserted; the wound was dressed with boracic acid lint and absorbent wool, and fifteen minims of tincture of opirm were ordered every four hours. On the second day after the operation her temperature rose to $99.2^{\circ}$, and this was its highest point during her illness; the wound healed in nearly its whole length by first intention, but a little suppuration at its lower corner delayed complete union until the end of a fortnight; the bowels were spontaneously opened at the end of nine days, and four weeks after the operation she was able to wear a truss and get about her daily work. I saw her a few weeks ago and then she was in perfect health and the hernia had not again come down.

CASE 2.-On April 26th, 1892, I was asked to see Mrs. $\mathrm{B}-$ - aged seventy-three years, Dr. Owen Roberts, her medical attendant, having discovered the presence of strangulated hernia. She only noticed the lump a fortnight ago, and on the 25th was seized with pain and vomiting, the bowels being constipated. In the right groin below Poupart's ligament was a small tense swelling, in which on coughing no impulse could be detected, and feeling as though it contained nuch fluid. The patient was also suffering from an almost continuous cough, the result of chronic bronchitis. Dr. Roberts having put the patient under the A.C.E. mixture taxis was tried; but the hernia not showing any tendency to go back I proceeded to operate and found, as I had suspected, that the sac contained much fluid. It contained omentum firmly adherent to the sac and a small knuckle of intestine of a deep claret colo:ir. The subsequent steps of the operation were similar to those in the preceding case, the omentum being ligatured with silk ligatures and the neck of the sac sewn up with the same. Seven days after the operation the wound had healed by 